Article

\title{
Effects of Rare Earth on the Microstructure and Impact Toughness of H13 Steel
}

\section{Jinzhu Gao, Paixian Fu *, Hongwei Liu and Dianzhong Li}

Shenyang National Laboratory for Materials Science, Institute of Metal Research, Chinese Academy of Sciences, 72 Wenhua Road, Shenyang 110016, China;

E-Mails: jzgao11b@imr.ac.cn (J.G.); hwliu@imr.ac.cn (H.L.); dzli@imr.ac.cn (D.L.)

* Author to whom correspondence should be addressed; E-Mail: pxfu@imr.ac.cn; Tel.: +86-24-2397-1973; Fax: +86-24-8397-0095.

Academic Editor: Anders E. W. Jarfors

Received: 19 January 2015 / Accepted: 16 February 2015 / Published: 11 March 2015

\begin{abstract}
Studies of H13 steel suggest that under appropriate conditions, additions of rare-earth metals (REM) can significantly enhance mechanical properties, such as impact toughness. This improvement is apparently due to the formation of finer and more dispersive RE inclusions and grain refinement after REM additions. In this present work, the microstructure evolution and mechanical properties of $\mathrm{H} 13$ steel with rare earth additions $(0,0.015,0.025$ and 0.1 wt. $\%)$ were investigated. The grain size, inclusions and fracture morphology were systematically studied by means of optical microscopy (OM), scanning electron microscopy (SEM) and transmission electron microscopy (TEM). The results indicate that REM addition of $0.015 \mathrm{wt} . \%$ can result in good improvement of performance compared to the REM additions of $0.025 \mathrm{wt} . \%$ and $0.1 \mathrm{wt} . \%$. It is found that the impact toughness is significantly enhanced with the addition of $0.015 \%$ REM, which can be improved $90 \%$ from $10 \mathrm{~J}$ to $19 \mathrm{~J}$. Such an addition of REM can result in a huge volume fraction of finer and more dispersive inclusions which are extremely good to toughness.
\end{abstract}

Keywords: rare earth metals (REM); H13 steel; impact toughness; inclusions 


\section{Introduction}

H13 steel is a kind of hot work die steel with high harden ability, good toughness, good heat resistance, thermal stability, antioxidant capacity and thermal fatigue behavior, which is widely used in hot-pressing, hot-extrusion and casting of dies [1,2]. In practical use, there are two main failure forms: one is fracture failure and the other thermal fatigue. Practically speaking, the early fracture of a hot-work due to the poor impact toughness is the main failure form $[3,4]$. The cracks are normally observed on the die surface as a network, which results in more than $80 \%$ failure of dies [5]. Therefore, increasing the impact toughness of dies is extremely important to increase the life of hot work die steels. To solve this problem, many studies have been done on the high temperature strength and the impact toughness of hot work die steels and a number of new types of hot work tool steels have been developed to improve such properties, They have found that the failure of $\mathrm{H} 13$ steel is mainly caused by the large and strip inclusions and the coarse microstructure [6-10]. These defects result in the increasing of brittleness of die and early cracking. Therefore, it is necessary to take some strengthening measures in order to improve the service life of dies. One of today's modern manufacturing techniques, such as electroslag remelting (ESR) technology, is a good method to refine the inclusions and microstructure, which is when the steel is with high purity and uniform microstructure. However, the disadvantage of ESR is the high cost of power and the pollution of the environment due to the slag containing CaF. Thus, it is necessary to use chemical modification by adding small quantities of some chemical elements.

Recently, many studies have showed that REM has the effect of improving the microstructure [11]. The addition of REM can not only purify the molten steel and improve microstructure, but can also modify the behaviors of inclusions. REM elements, such as cerium and lanthanum, can form extremely stable oxides, oxy-sulfides and sulfides [12,13]. The Gibbs' free energies of these compounds at high temperatures are so low that REM elements can combine readily with oxygen and sulfur when added to liquid steel [14]. The melting temperatures of these compounds are quite high [15]. Therefore, they can precipitate as solid particles in liquid steel as $\mathrm{Al}_{2} \mathrm{O}_{3}$ inclusions. Because of their strong affinity with oxygen and sulfur, REM elements have been used in both deoxidation and desulfurization steels. Unfortunately, the oxides, sulfides and oxy-sulfides of the REM have similar densities compared to that of liquid steel. Therefore, once formed, the removal of inclusions is relatively difficult. There have been a number of researches pertaining to the application of REM elements in molten steel. Substantial improvements have been achieved in mechanical properties due to the modifications of the morphology and size of inclusions [16-26]. However, the purity of steel can be declined and some important properties deteriorated when the REM addition technology is improperly used, such as the unreasonable amounts of REM addition, which will eventually affect the application of REM in the steel.

Recently, there have been few works relating to the application of REM in improving the mechanical properties of the H13 hot work die steels. Therefore, the purpose of this paper is to discuss the effects of moderate amounts of REM on the microstructure and mechanical properties of H13 steel, focusing on the relationship between REM contents and the mechanical properties. 


\section{Experimental Section}

The material investigated in this work is H13 steel. The compositions of H13 steel are listed in Table 1 . The alloy was melted in a $25 \mathrm{~kg}$ capacity medium frequency induction furnace. Once the alloy was melted in a furnace under argon gas atmosphere, about $0.1 \%$ pure aluminum was added to deoxidize the melt. The REM (mainly containing $30 \% \mathrm{La}$ and $65 \% \mathrm{Ce}$ ) was added into the molten steel under the atmosphere when the oxygen content in molten steel was reduced to low level. Different amounts of REM were added into the melt, wrapped in aluminum foil, stirred to ensure the homogeneity of compositions. The residual amounts of REM in steel were $0 \%, 0.015 \%, 0.025 \%$ and $0.1 \%$, respectively, as shown in Table 1.

In the forging process, the initial forging temperature and final forging temperature are $1150{ }^{\circ} \mathrm{C}$ and $900^{\circ} \mathrm{C}$. All the ingots were rapidly water cooled down to room temperature after forging. The final size of forging ingots was $70 \mathrm{~mm} \times 70 \mathrm{~mm} \times 500 \mathrm{~mm}$. Then the spheroidizing annealing was carried out, which the temperature was raised to $870{ }^{\circ} \mathrm{C}$ for $2 \mathrm{~h}$, then cooled to $740{ }^{\circ} \mathrm{C}$ for $4 \mathrm{~h}$, eventually furnace cooled to room temperature. The forging and heat treatment of all samples are the same.

The impact toughness was determined after quenching and tempering. The heat treatment of the specimens consisted of austenitizing at $1020{ }^{\circ} \mathrm{C}$ for $40 \mathrm{~min}$ with subsequent oil cooling to room temperature. Afterward, the samples were two times tempering, the temperature was $610{ }^{\circ} \mathrm{C}$ and $600{ }^{\circ} \mathrm{C}$ for $2 \mathrm{~h}$. The impact tests were carried out at room temperature $\left(\approx 20^{\circ} \mathrm{C}\right)$. The specimens for charpy $\mathrm{v}$-notch impact was prepared by spark cutting and then mechanically polished, which dimensions were $10 \mathrm{~mm} \times 10 \mathrm{~mm} \times 55 \mathrm{~mm}$. The impact performance tests were conducted according to the standard method NADCA \#207-2003 by using ZBC2452-C type test machine (Meitesi Industry System China Co., Ltd., Shenzhen, China).

Metallographic observations were carried out on the specimens subjected to casted state and heat treatment state. The statistic of grain size and inclusions were examined by using image statistic analysis. The types of inclusions and the observation of fracture morphology were extensively analyzed by SEM (JSM-6301F, Japan Electronics Corporation, Tokyo, Japan) equipped with energy dispersive X-ray spectroscopy (EDX), which demonstrated which specimens were impact tests. In addition, the morphology and the types of the inclusions in the matrix were analyzed by TEM. The samples for TEM observation were prepared by spark cutting and machinery polishing. Then samples were then reduced by using iron etching device. The TEM observation was conducted by using F20 (FEI company, Hillsboro, OR, USA), which is also equipped with an Oxford INCA type spectrometer (Japan Electronics Corporation, Tokyo, Japan) and GATAN 832 CCD image recorder (Japan Electronics Corporation, Tokyo, Japan).

Table 1. The compositions of $\mathrm{H} 13$ steel ingots (wt $\%$ ).

\begin{tabular}{cccccccccc}
\hline Ingots & $\mathbf{C}$ & Si & Mn & S & Cr & Mo & V & REM & O \\
\hline $1 \#$ & 0.38 & 1.2 & 0.47 & 0.005 & 4.90 & 1.40 & 1.05 & 0 & 0.001 \\
$2 \#$ & 0.38 & 1.18 & 0.49 & 0.001 & 5.02 & 1.40 & 1.06 & 0.015 & 0.0002 \\
$3 \#$ & 0.38 & 1.2 & 0.49 & 0.001 & 4.94 & 1.39 & 1.06 & 0.025 & 0.0004 \\
$4 \#$ & 0.38 & 1.2 & 0.49 & 0.001 & 4.94 & 1.39 & 1.06 & 0.1 & 0.0006 \\
\hline
\end{tabular}




\section{Results and Discussion}

\subsection{The Analysis of the Microstructure after REM Addition}

The grain size of casted steel with different contents of REM is shown in Figure 1. It is obviously seen that the grain size of REM free (see Figure 1a) is relatively larger compared to the ingots with REM treated (see Figure 1b-d). Through the statistic analysis of the images, the average grain size is about $50 \mu \mathrm{m}$ without REM as shown in Figure 3a, while it can reach to $25 \mu \mathrm{m}$ approximately after REM addition, indicating that obvious grain refinement takes place in casted state. The grain size after heat treatment state is shown in Figure 2. It can be seen that the grain size of the REM treated grain (see Figure $2 b-d$ ) is still smaller compared to the ingots without REM (see Figure 2a). Through the statistic analysis of the images, the average grain size is about $20 \mu \mathrm{m}$ without REM while it can reach to $8 \mu \mathrm{m}$ approximately after REM addition as shown in Figure 3b. It was found that the grain size changed 2.5 times from $50 \mu \mathrm{m}$ to $20 \mu \mathrm{m}$ without REM after heat treatment, which changed 3.1 times from $25 \mu \mathrm{m}$ to $8 \mu \mathrm{m}$ with REM treated after heat treatment. It is indicated that effect of REM on grain refinement is not obvious after heat treatment, which occurred mainly in the casted state.
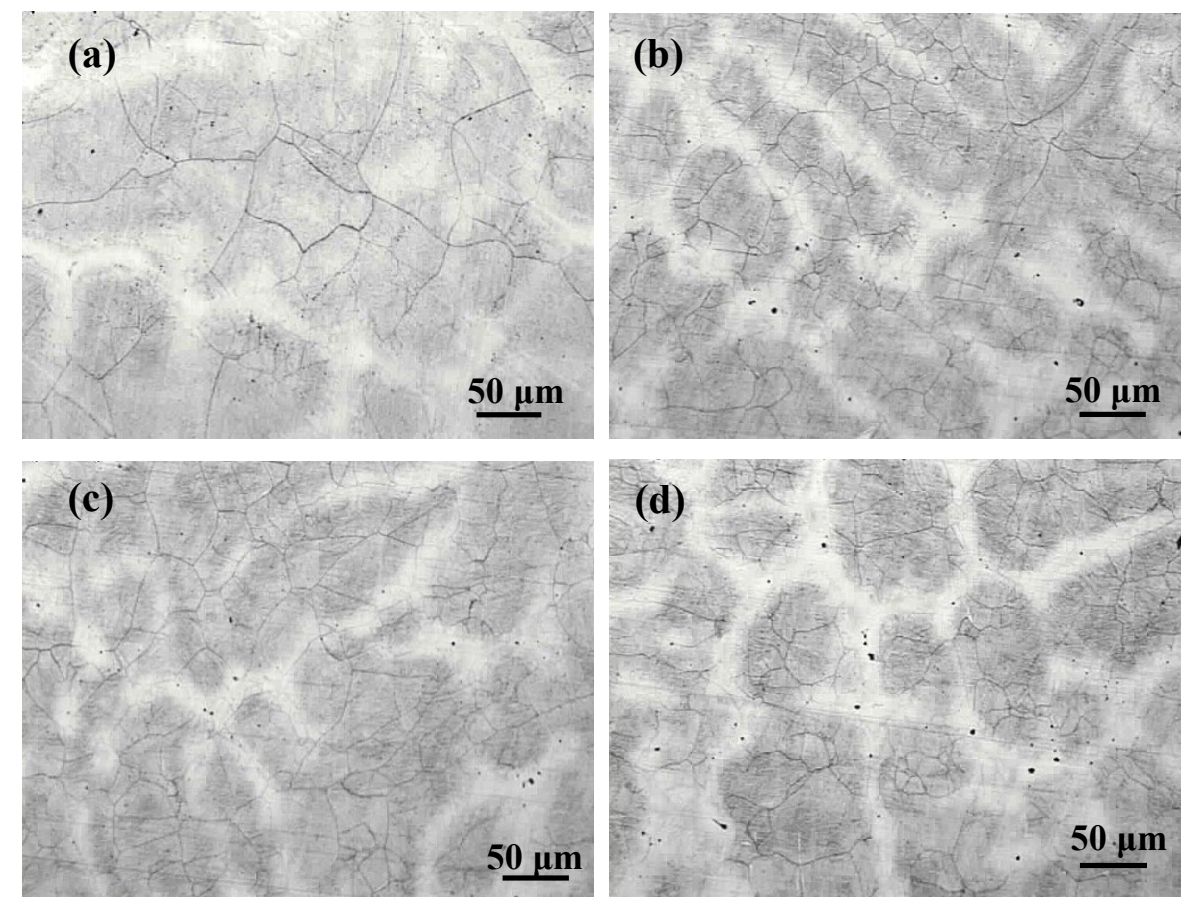

Figure 1. The grain size of casted steels with different contents of REM (a) 1\# ingot without REM; (b) 2\# ingot with 0.015\% REM; (c) 3\# ingot with 0.025\% REM; (d) 4\# ingot with $0.1 \%$ REM.

The effect of REM on the morphology of inclusions is shown in back-scattered electron micrographs in Figure 4. Figure 4a shows the micrograph of inclusion distribution without REM, which reveals coarse inclusions in the metal matrix. Figure $4 \mathrm{~b}$ represents the micrograph of inclusion distribution with $0.015 \%$ REM. It can be clearly observed that the size of inclusions decrease with the addition of REM. Figure $4 \mathrm{c}, \mathrm{d}$ show the micrograph of inclusion distribution with the REM additions of $0.025 \%$ and $0.1 \%$, respectively. It has been found that the size of inclusions increased with the increasing REM content, 
which indicating that the amounts of REM should be added properly. The typical EDS of inclusions without REM and after REM addition are shown in Figure 5. It is observed from Figure 5a that mainly these types of inclusions consist of $\mathrm{Al}_{2} \mathrm{O}_{3}$ and $\mathrm{MnS}$. The inclusions after REM additions, as shown in Figure 5b, mainly contain REM, sulfur and oxygen as determined by energy spectrometry. These particles are believed to be RE oxy-sulfides and were the most common form of inclusion found in this experiment.
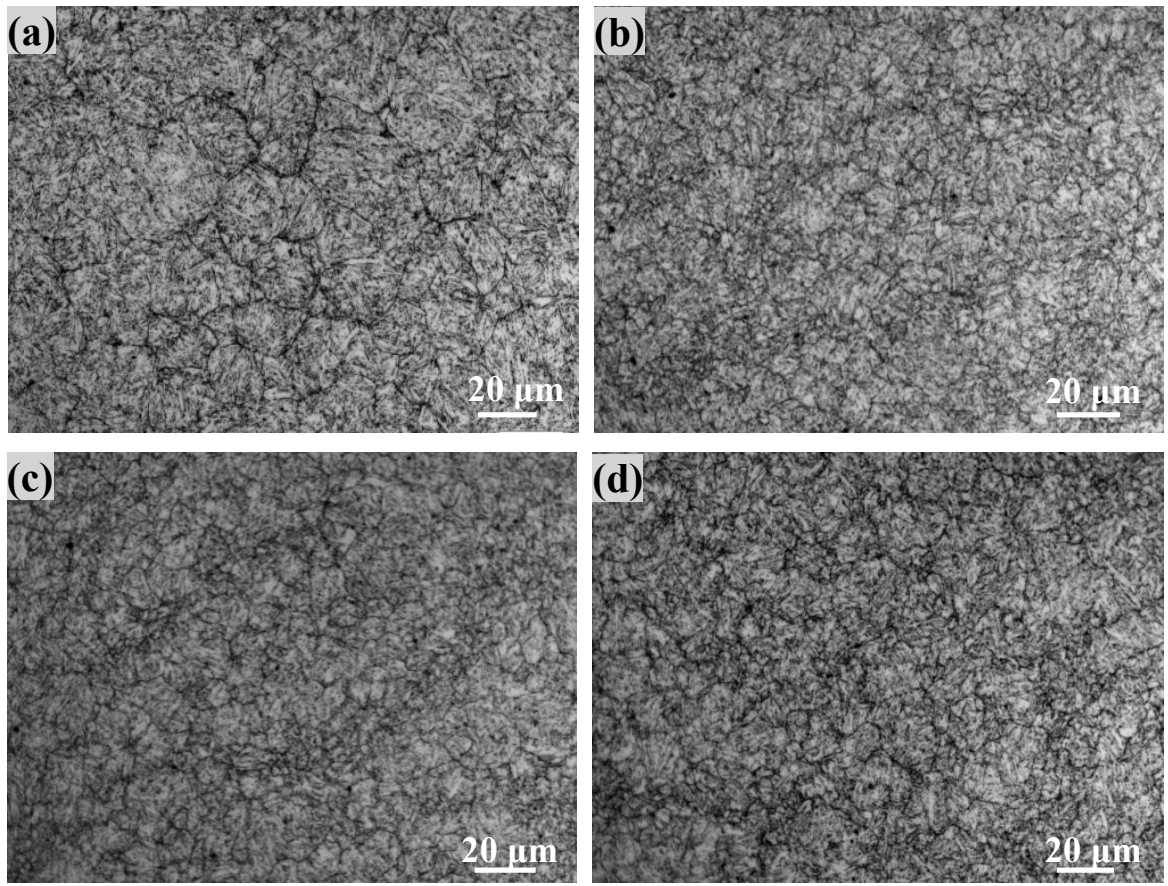

Figure 2. The grain size after heat treatment with different contents of REM (a) 1\# ingot without REM; (b) 2\# ingot with $0.015 \%$ REM; (c) 3\# ingot with $0.025 \%$ REM; (d) 4 \# ingot with $0.1 \%$ REM.
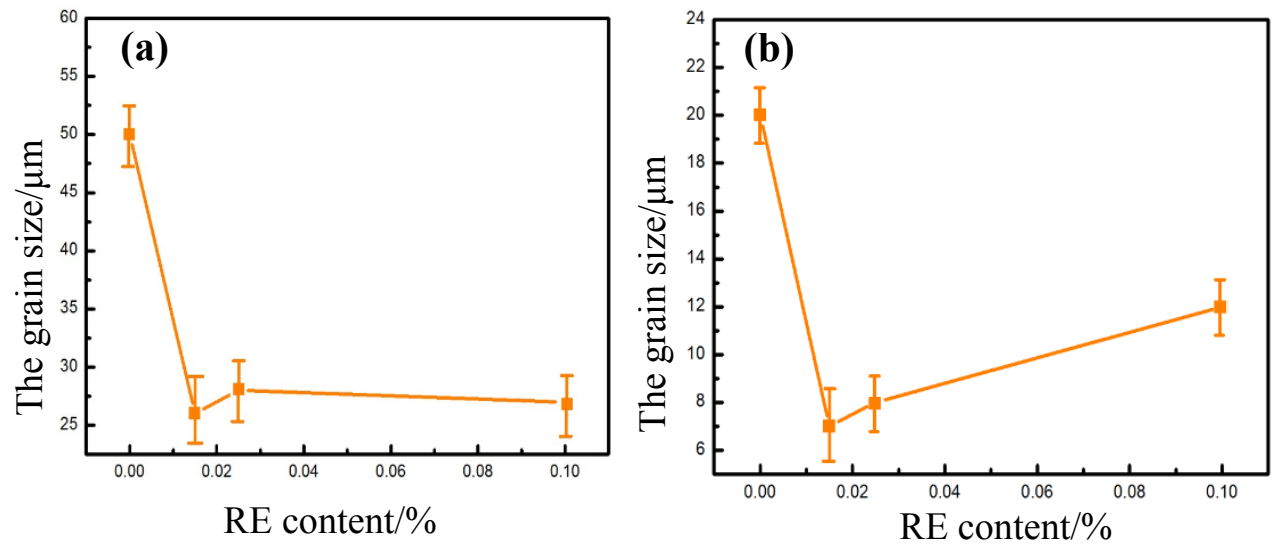

Figure 3. The grain refinement for the casted state (a) and after heat treatment; (b) tested by image statistic analysis. 

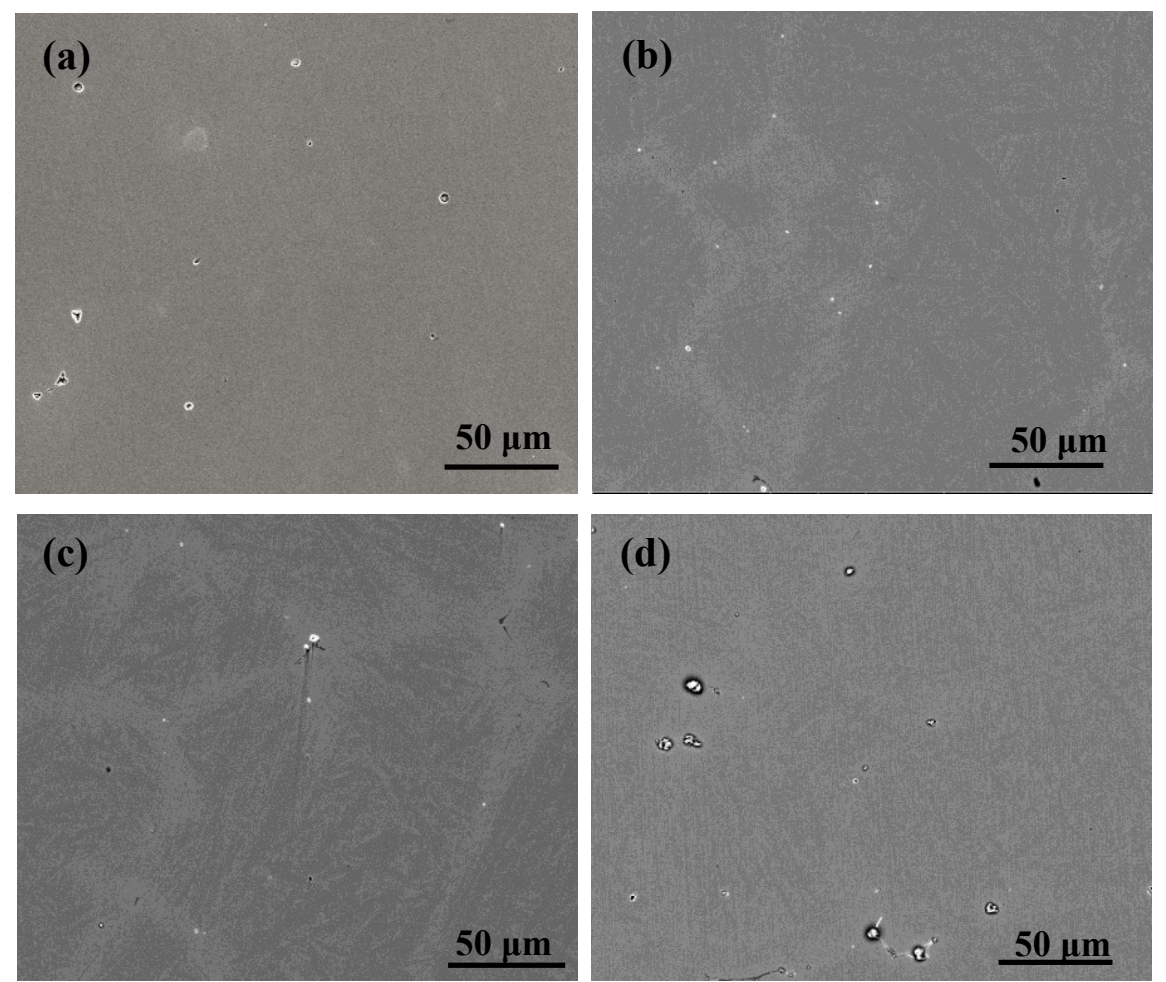

Figure 4. The back-scattered electron micrographs of the inclusions after REM addition (a) 1\# ingot with $0 \%$ REM; (b) 2\# ingot with $0.015 \%$ REM; (c) $3 \#$ ingot with $0.025 \%$ REM; (d) 4 \# ingot with $0.1 \%$ REM.

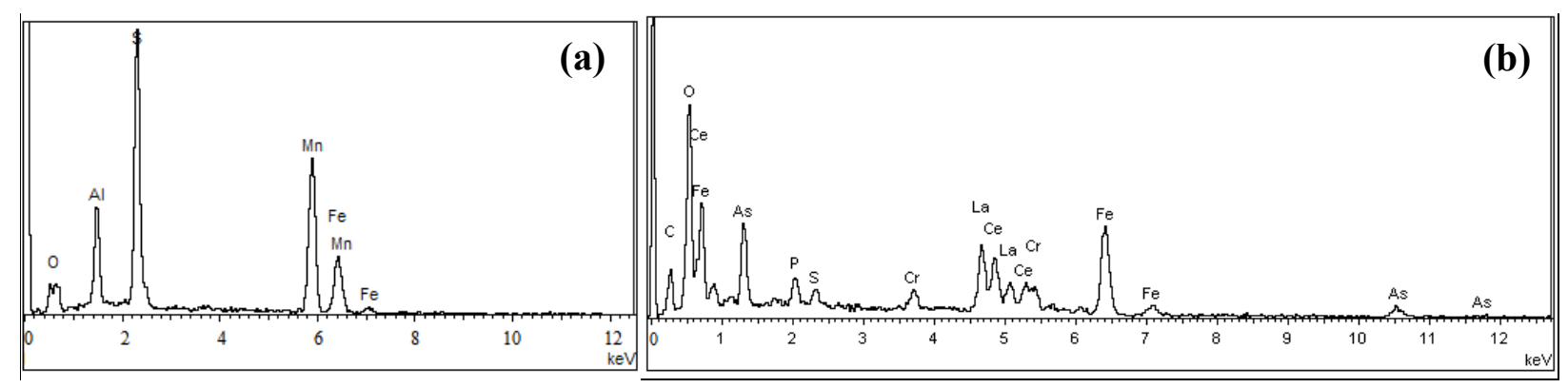

Figure 5. The typical EDS analysis of inclusions without REM (a) and after REM addition (b).

Table 2. The relation of longitudinal length and number percentage of inclusions tested by image statistic analysis [\%].

\begin{tabular}{cccccc}
\hline Ingots & $\mathbf{0 - 1} \boldsymbol{\mu m}$ & $\mathbf{1 - 2} \boldsymbol{\mu m}$ & $\mathbf{2 - 5} \boldsymbol{\mu m}$ & $\mathbf{5}-\mathbf{1 0} \boldsymbol{\mu m}$ & $>\mathbf{1 0} \boldsymbol{\mu m}$ \\
\hline $1 \#$ & 0 & 7 & 22 & 69 & 2 \\
$2 \#$ & 19 & 71 & 8 & 2 & 0 \\
$3 \#$ & 5 & 40 & 45 & 8 & 2 \\
$4 \#$ & 2 & 10 & 68 & 15 & 5 \\
\hline
\end{tabular}

Table 2 shows the quantitative relation of longitudinal length and number percentage of inclusions tested by image statistic analysis. As seen, the percentage of small size of inclusions $(<2 \mu \mathrm{m})$ increases with the addition of $0.015 \%$ REM, is $90 \%$. However, the percentage of small size of inclusions $(<2 \mu \mathrm{m})$ 
decreases with the increasing of REM. It should be noted that the change in size of inclusions is important since it has a direct influence on the mechanical properties. On the other hand, adding appropriate elements of $0.015 \%$ REM to the alloy caused an increasing in the percentage of small size of inclusions from $7 \%$ in steel No. 1 to $71 \%$ in steel No. 2 .

\subsection{The Analysis of Grain Refinement}

Many literatures have reported the mechanism of grain refinement of REM addition, which shows which numbers of grains are nucleated through heterogeneous nucleation. It has been reported that REM addition can refine the grain refinement because the RE oxide inclusions can act as the heterogeneous nuclei. These inclusions must have two conditions to become effective heterogeneous nuclei [27-29].

First, the lattice misfit between the inclusions and the matrix must be less than $6 \%$. Secondly, the melting point of these inclusions must be higher than the solidification temperature.

TEM analysis of REM inclusions was performed on the samples, and the results are shown in Figure 6. Figure 6a shows the TEM image of inclusion, it is seen that the size of this inclusion is $300 \mathrm{~nm}$ and its shape is spherical. According to the analysis of the result of EDS (see Figure 6b), the inclusion is mainly composed of cerium, oxygen and sulfur. The inclusion, $\mathrm{Ce}_{2} \mathrm{O}_{2} \mathrm{~S}$, is identified by their diffraction patterns (see Figure 6c). High-resolution transmission electron microscopy (HRTEM) observations (see Figure 6d) show that the direction and spacing of interface between inclusion and matrix are basically the same, which indicate that the lattice misfit between the inclusions and the matrix is lower.
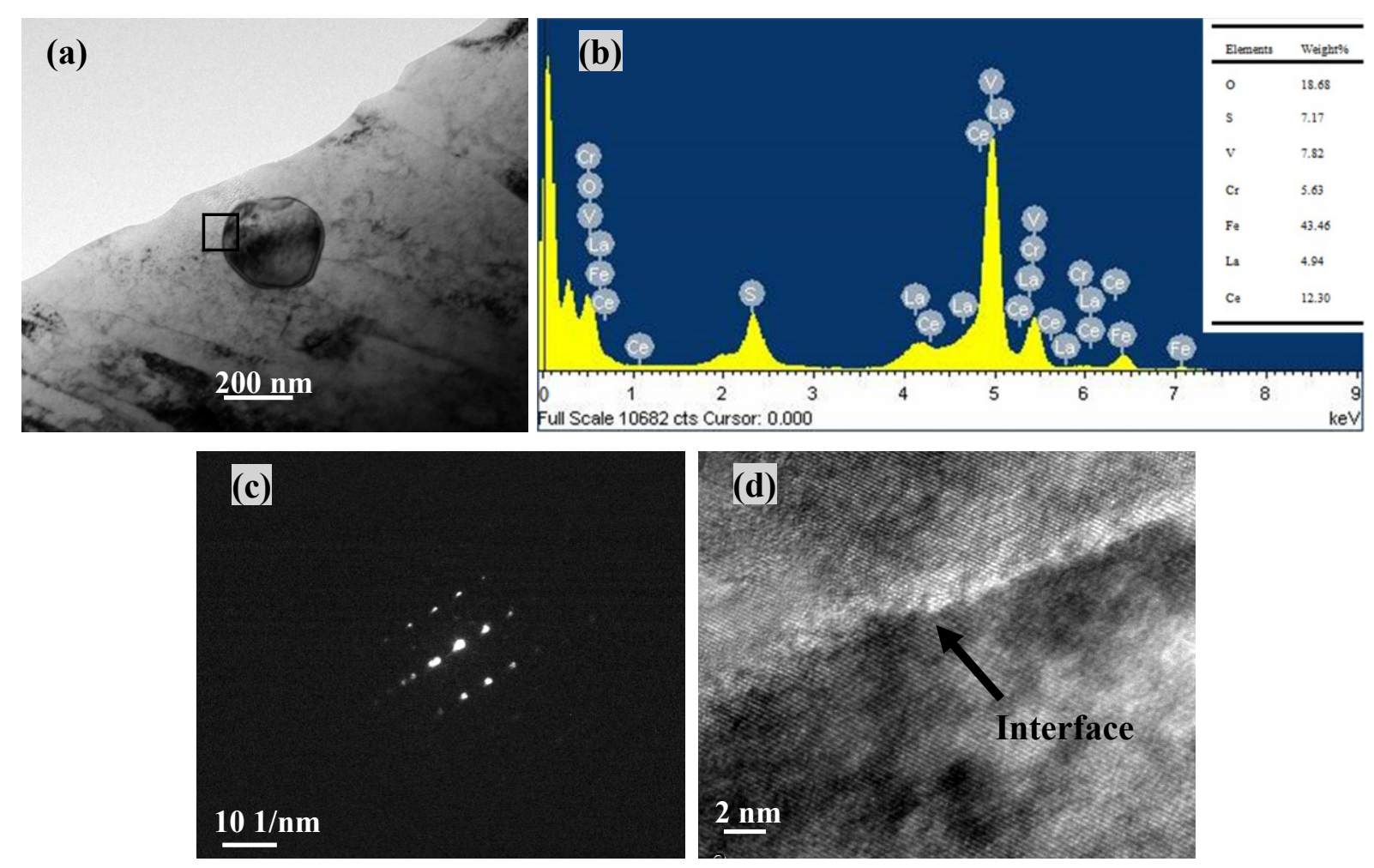

Figure 6. RE inclusion analyzed by TEM: (a) TEM image of inclusion; (b) EDS analysis of inclusion; (c) Diffraction patterns for corresponding to the inclusion; (d) HRTEM of the inclusion. 
According to the formula in Ref. [29], the $\Delta \mathrm{G}$ of $\mathrm{Ce}_{2} \mathrm{O}_{2} \mathrm{~S}$ at the temperature of $1500{ }^{\circ} \mathrm{C}$ is $-576,367 \mathrm{~J} / \mathrm{mol}$, which indicates that $\mathrm{Ce}_{2} \mathrm{O}_{2} \mathrm{~S}$ can be formed at the temperature of $1500{ }^{\circ} \mathrm{C}$, and can exist in the melt when REM is added.

The boundary energy between the heterogeneous nuclei and the crystallization phase has an effect on nucleus formation and it depends on the structure of the two contacting crystalline faces (arrangement condition, atom size and interatomic spacing of the crystal faces) [28]. The value of the two-dimensional lattice misfits usually evaluated where some inclusions may act as the heterogeneous nuclei. The two-dimensional lattice disregistry mathematical model from Bramfitt [30] is:

$$
\delta_{(h k)_{n}}^{(h k l)}=\sum_{i=1}^{3} \frac{\frac{\mid\left(d[u v w]_{s}^{i} \cos \theta-d[u v w]_{n}^{i} \mid\right.}{d_{(u w w)_{n}^{i}}}}{3} \times 100 \%
$$

where, $(h k l)_{s}$ is the low index planner of inclusion, $[u v w]_{\mathrm{s}}$ is the low index direction of $(h k l)_{s},(h k l)_{n}$ is the low index planner of matrix, $[u v w]_{n}$ is the low index direction of $(h k l)_{n}, \mathrm{~d}[u v w]_{s}$ is the interatomic spacing of $[u v w]_{s}, \mathrm{~d}[u v w]_{n}$ is the interatomic spacing of $[u v w]_{n}, \theta$ is the angle between $[u v w]_{n}$ and $[u v w]_{s}$.

The relationship of crystal orientation between low index crystal faces of matrix $(\delta-\mathrm{Fe})$ and $\mathrm{Ce}_{2} \mathrm{O}_{2} \mathrm{~S}$ is shown in Figure 7. Results of calculation of two-dimensional lattice disregistry are shown in Table 3. The lattice disregistry between $(0001) \mathrm{Ce}_{2} \mathrm{O}_{2} \mathrm{~S}$ and (111) $\delta$-Fe is $3.5 \%$, which is less than $6 \%$. Therefore, the $\mathrm{Ce}_{2} \mathrm{O}_{2} \mathrm{~S}$ can act as heterogeneous nucleation.

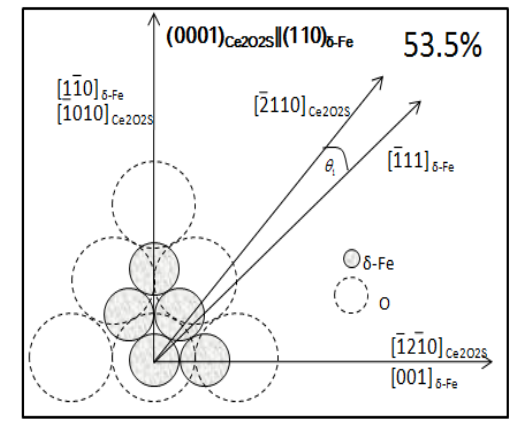

(a)

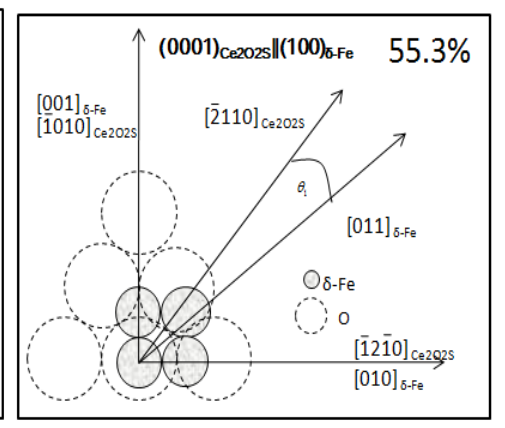

(b)

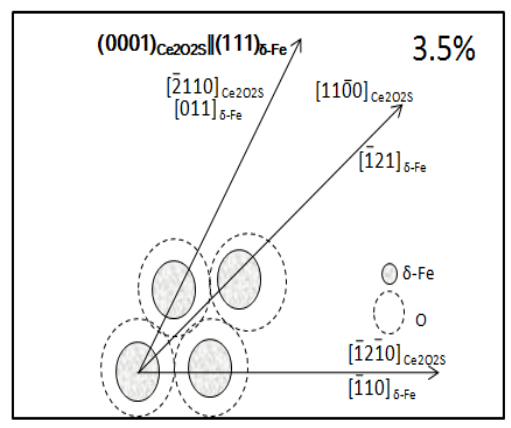

(c)

Figure 7. Relationship of crystallizing planes of $\mathrm{Ce}_{2} \mathrm{O}_{2} \mathrm{~S}$ and $\delta$-Fe. (a) between (0001) of $\mathrm{Ce}_{2} \mathrm{O}_{2} \mathrm{~S}$ and the (110) of $\delta$-Fe; (b) between (0001) of $\mathrm{Ce}_{2} \mathrm{O}_{2} \mathrm{~S}$ and the (110) of $\delta$-Fe; (c) between (0001) of $\mathrm{Ce}_{2} \mathrm{O}_{2} \mathrm{~S}$ and the (111) of $\delta$-Fe.

Table 3. Results of calculation of two-dimensional lattice disregistry.

\begin{tabular}{|c|c|c|c|c|c|c|c|}
\hline case & {$[h k l]_{s}$} & {$[h k l]_{n}$} & $\mathrm{~d}[h \boldsymbol{k} l]_{s} / \mathbf{n m}$ & $\mathrm{d}[h k l]_{n} / \mathrm{nm}$ & $\theta_{1} /{ }^{\circ}$ & $\mathrm{d}[h k l]_{s} \cdot \cos \theta_{1} / \mathrm{nm}$ & $\delta$ \\
\hline \multirow{3}{*}{$(0001) \mathrm{Ce}_{2} \mathrm{O}_{2} \mathrm{~S} / /(110)_{\delta-\mathrm{Fe}}$} & {$[1210] \mathrm{Ce}_{2} \mathrm{O}_{2} \mathrm{~S}$} & {$[001]_{\delta-\mathrm{Fe}}$} & 0.4 & 0.29315 & 0 & 0.4 & \multirow{3}{*}{$53.5 \%$} \\
\hline & {$[2110] \mathrm{Ce}_{2} \mathrm{O}_{2} \mathrm{~S}$} & {$[111]_{\delta-\mathrm{Fe}}$} & 0.4 & 0.25388 & 5.3 & 0.3983 & \\
\hline & {$[1010] \mathrm{Ce}_{2} \mathrm{O}_{2} \mathrm{~S}$} & {$[110]_{\delta-\mathrm{Fe}}$} & 0.6928 & 0.41457 & 0 & 0.6928 & \\
\hline \multirow{3}{*}{$(0001) \mathrm{Ce}_{2} \mathrm{O}_{2} \mathrm{~S} / /(100)_{\delta-\mathrm{Fe}}$} & {$[1210] \mathrm{Ce}_{2} \mathrm{O}_{2} \mathrm{~S}$} & {$[010]_{\delta-\mathrm{Fe}}$} & 0.4 & 0.29315 & 0 & 0.4 & \multirow{3}{*}{$55.3 \%$} \\
\hline & {$[2110] \mathrm{Ce}_{2} \mathrm{O}_{2} \mathrm{~S}$} & {$[011]_{\delta-\mathrm{Fe}}$} & 0.4 & 0.41457 & 15 & 0.3864 & \\
\hline & {$[1010] \mathrm{Ce}_{2} \mathrm{O}_{2} \mathrm{~S}$} & {$[001]_{\delta-\mathrm{Fe}}$} & 0.6928 & 0.29315 & 0 & 0.6928 & \\
\hline \multirow{3}{*}{$(0001) \mathrm{Ce}_{2} \mathrm{O}_{2} \mathrm{~S} / /(111)_{\delta-\mathrm{Fe}}$} & {$[1210] \mathrm{Ce}_{2} \mathrm{O}_{2} \mathrm{~S}$} & {$[110]_{\delta-\mathrm{Fe}}$} & 0.4 & 0.41457 & 0 & 0.4 & \multirow{3}{*}{$3.5 \%$} \\
\hline & {$[1100] \mathrm{Ce}_{2} \mathrm{O}_{2} \mathrm{~S}$} & {$[121]_{\delta-\mathrm{Fe}}$} & 0.6928 & 0.71806 & 0 & 0.6928 & \\
\hline & {$[2110] \mathrm{Ce}_{2} \mathrm{O}_{2} \mathrm{~S}$} & {$[011]_{\delta-\mathrm{Fe}}$} & 0.4 & 0.41457 & 0 & 0.4 & \\
\hline
\end{tabular}




\subsection{The Analysis of Impact Toughness after REM Addition}

Figure 8 shows the typical curve of the impact toughness with different levels of REM at room temperature. It is found that the impact toughness is significantly enhanced with the addition of $0.015 \%$ REM, which can be improved $90 \%$ from $10 \mathrm{~J}$ to $19 \mathrm{~J}$. In addition, it is easily seen that the toughness gradually decreases with the increasing addition of REM, when the addition amount of REM increases up to $0.1 \%$, the impact toughness is decreased by $21 \%$ from $19 \mathrm{~J}$ to 14 J. J.J. Moore [24] firstly reported the effect of REM addition on the enhancement of mechanical properties. The focus of his work was to desulfurize sand cast steels to improve impact toughness. He produced a $0.1 \% \mathrm{C}, 1.25 \% \mathrm{Mn}$ steel which was poured into cylindrical resin-bonded sand molds. Both mischmetal and RE silicide additions were examined. The sulfur level in the steel matrix was reduced by $90 \%$. The sulfur was found to be tied up in the complex oxy-sulfides. Moore noticed a reduction in grain size, but attributed the improvement in properties to a reduction in sulfur content in the steel matrix. It is recently reported that the transverse impact value of $2 \mathrm{Cr} 13$ stainless steel has been improved obviously by REM [31]. The transverse impact value of RE-2Cr13 is increased by $54.55 \%$ at the temperature of $-40{ }^{\circ} \mathrm{C}$, comparing with $0 \% \mathrm{RE}-2 \mathrm{Cr} 13$. In addition, Hamidzadehn et al., reported that the toughness of AISI D2 tool steel increased about $75 \%$ without reducing the hardness of the alloy after Ce/La modification [32].

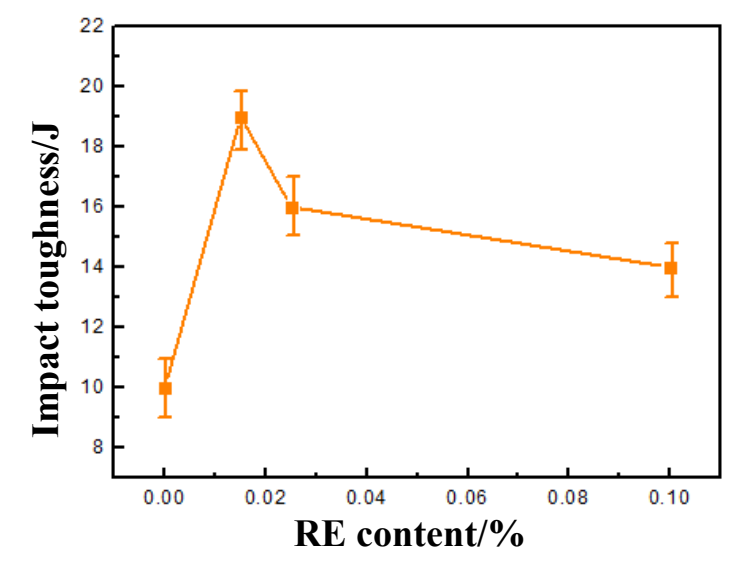

Figure 8. The impact toughness of H13 steel.

The impact toughness of H13 steel mainly depends on size of grain and inclusions. The effective ways of improving steel properties are by refining its microstructure and making inclusions fine and dispersive, which can ease the stress concentration and increase the toughness. The major reason for improvement in toughness is refining the grain size and uniform and fine distribution of inclusions after adding REM.

Figure 9 presents the typical fracture morphology of $\mathrm{H} 13$ steel with various concentration of REM. Under the RE-free conditions, the fracture surfaces are mainly covered by cleavage plane, as shown in Figure 9a. It is shown the fracture of the alloy occurs generally in brittle pattern. When the addition amount of REM rises to $0.015 \%$, it is clearly observed from Figure $9 \mathrm{~b}$ that the fracture surfaces are composed of many dimples. Figure $9 \mathrm{c}$ and d show the typical fracture morphology of H13 steel with the addition of $0.025 \%$ REM and $0.1 \%$ REM. It is obvious that some cleavage planes and few dimples are 
formed on the fracture surfaces. The results of fracture surfaces indicate that a brittle failure type for H13 steel without REM concentration, and a ductile failure type for H13 steel with $0.015 \%$ REM.
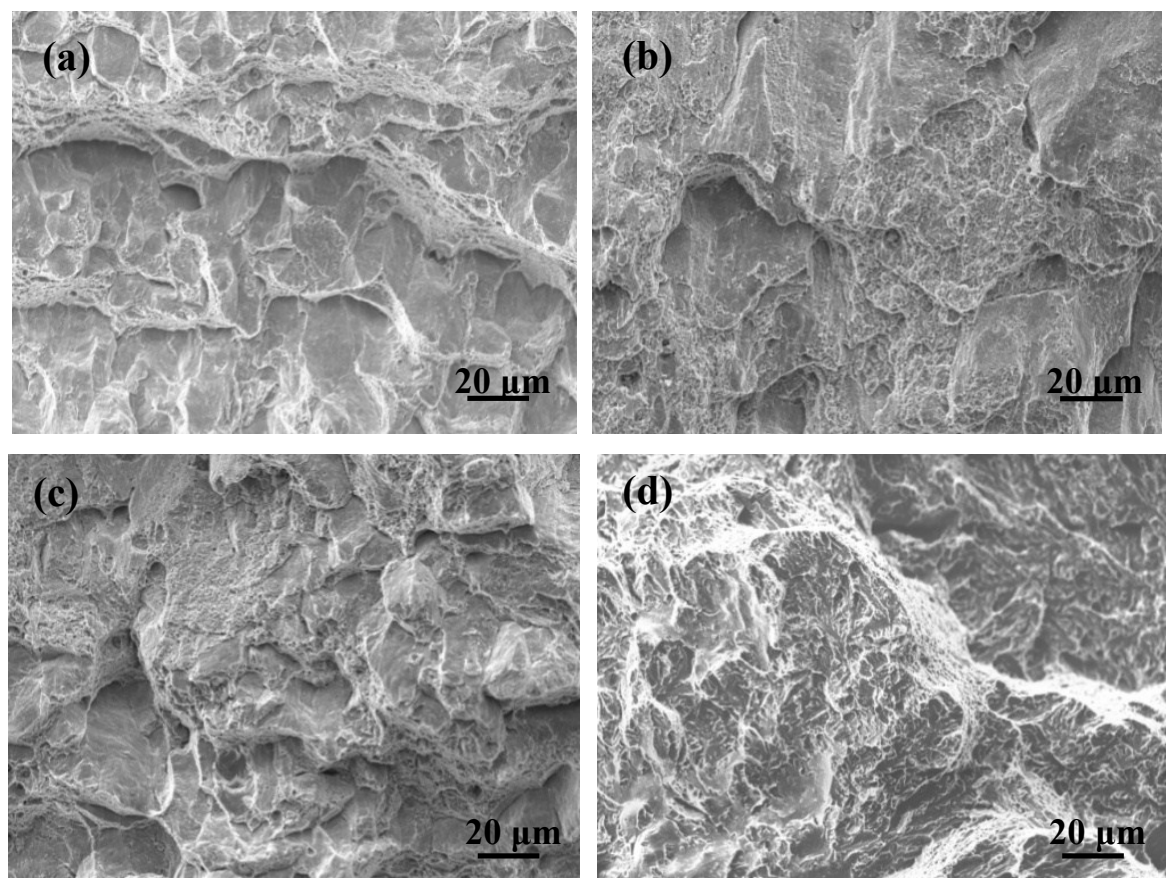

Figure 9. The typical fracture morphology of $\mathrm{H} 13$ steel (a) $1 \#$ ingot with $0 \%$ REM; (b) 2\# ingot with $0.015 \%$ REM; (c) 3\# ingot with $0.025 \%$ REM; (d) $4 \#$ ingot with $0.1 \%$ REM.

\section{Conclusions}

The effect of different amounts of REM on the microstructure and mechanical properties of H13 steel was studied. The following conclusions were drawn:

(1) REM can significantly refine the grain size so that its size decreases from $50 \mu \mathrm{m}$ to $25 \mu \mathrm{m}$ in the casted state. Effect of REM on grain refinement is not obvious after heat treatment, which occurred mainly in the casted state.

(2) REM can obviously modify the inclusions in H13 steel, which adding an appropriate amount of REM can significantly refine the size of inclusions that the percentage of small size of inclusions $(<2 \mu \mathrm{m})$ increases with the addition of $0.015 \%$ REM, is $90 \%$. However, the percentage of small size of inclusions $(<2 \mu \mathrm{m})$ decreases with the increasing addition of REM.

(3) Due to the refinement of grain and modification of inclusions, the impact toughness is significantly enhanced with the addition of $0.015 \%$ REM, which gradually decreases with the increasing addition of REM because of the formation of large inclusions.

\section{Acknowledgments}

This research is financially supported by the Program of Strategic Priority Research under Grand No.XDA03010304. 


\section{Author Contributions}

Jinzhu Gao carried out the experiments and analysis of the results; Paixian Fu and Hongwei Liu prepared and revised the manuscript; Dianzhong Li contributed in the interpretation and discussion of results.

\section{Conflicts of Interest}

The authors declare no conflict of interest.

\section{References}

1. Rafi, H.K.; Ram, G.; Phanikumar, G.; Rao, K.P. Microstructural evolution during friction surfacing of tool steel H13. Mater. Design 2011, 32, 82-87.

2. Taktak, S. Some mechanical properties of borided AISI H13 and 304 steels. Mater. Design 2007, 28, 1836-1843.

3. Li, G.; Li, X.; Wu, J. Study of the thermal fatigue crack initial life of H13 and H21 steels. J. Mater. Process. Technol. 1998, 74, 23-26.

4. Arif, A.; Sheikh, A.; Qamar, S. A study of die failure mechanisms in aluminum extrusion. J. Mater. Process. Technol. 2003, 134, 318-328.

5. Tsujii, N.; Abe, G.; Fukaura, K.; Sunada, H. High temperature low cycle fatigue behaviour of a 4.2 Cr-2.5 Mo-V-Nb hot work tool steel. J. Mater. Sci. Lett. 1996, 15, 1251-1254.

6. Hu, X.; Li, L.; Wu, X.; Zhang, M. Coarsening behavior of M23C6 carbides after ageing or thermal fatigue in AISI H13 steel with niobium. Int. J. Fatigue 2006, 28, 175-182.

7. Sjöström, J. Chromium Martensitic Hot-Work Tool Steels: Damage, Performance and Microstructure. Master Thesis, Karlstad University, Karlstad, Sweden, 2004.

8. Kchaou, M.; Elleuch, R.; Desplanques, Y.; Boidin, X.; Degallaix, G. Failure mechanisms of H13 die on relation to the forging process-A case study of brass gas valves. Eng. Fail. Anal. 2010, 17, 403-415.

9. Bahrami, A.; Anijdan, S.; Golozar, M.; Shamanian, M.; Varahram, N. Effects of conventional heat treatment on wear resistance of AISI H13 tool steel. Wear 2005, 258, 846-851.

10. Rong, W. Fracture analysis on 8407 steel die for Aiuminium pressure-casting. Heat Treat. Met. 2007, 243-245.

11. Garrison, W.M.; Maloney, J.L. Lanthanum additions and the toughness of ultra-high strength steels and the determination of appropriate lanthanum additions. Mater. Sci. Eng. A 2005, 403, 299-310.

12. Luyckx, L. The rare earth metals in steel. Ind. Appl. Rare Earth Elem. 1980, 32, 43.

13. Luyckx, L. Current trends in the use of rare earths in steelmaking. In Proceedings of the Electric Furnace Conference, Cincinnati, OH, USA, 5-7 December 1973.

14. Vahed, A.; Key, A.R. Thermodynamics of rare earths in steelmaking metall. Trans. $B$ 1976, $7 B$, 375-383.

15. Waubdy, P.E. Rare earth addition to steel. Int. Met. Rev. 1978, 2, 74-99.

16. Hamidzadeh, M.A.; Meratian, M.; Saatchi, A. Effect of cerium and lanthanum on the microstructure and mechanical properties of AISI D2 tool steel. Mater. Sci. Eng. A 2013, 571, 193-198. 
17. Cosandey, F.; Li, D.; Sczerzenie, F.; Tien, J. The effect of cerium on high temperature tensile and creep behavior of a superalloy. Metall. Trans. A 1983, 14, 611-621.

18. Fu, H.; Xiao, Q.; Kuang, J.; Jiang, Z.; Xing, J. Effect of rare earth and titanium additions on the microstructures and properties of low carbon Fe-B cast steel. Mater. Sci. Eng. A 2007, 466, 160-165.

19. Li, H.; McLean, A.; Rutter, J.; Sommerville, I. Influence of rare earth metals on the nucleation and solidification behavior of iron and 1045 steel. Metall. Trans. B 1988, 19, 383-395.

20. Lin, Q.; Guo, F.; Zhu, X. Behaviors of lanthanum and cerium on grain boundaries in carbon manganese clean steel. J. Rare Earths 2007, 25, 485-489.

21. Liu, C.; Huang, Y.; Jiang, M. Effects and mechanisms of RE on impact toughness and fracture toughness of clean heavy rail steel. J. Iron. Steel. Res. Int. 2011, 18, 52-58.

22. Liu, H.; Liu, C.; Jiang, M. Effect of rare earths on impact toughness of a low-carbon steel. Mater. Design 2012, 33, 306-312.

23. Tuttle, R. Effect of rare earth addition on grain refinement of plain carbon steels. Int. J. Metalcasting 2012, 1, 51-63.

24. Wang, L.; Du, X.; Gan, Y.; Liu, L.; Ye, X.; Jiang, L. Effect of rare earths on oxidation resistance of heat resistant steel. J. Rare Earths 2010, 28, 489-491.

25. Wang, L.; Lin, Q.; Yue, L.; Liu, L.; Guo, F.; Wang, F. Study of application of rare earth elements in advanced low alloy steels. J. Alloys Compd. 2008, 451, 534-537.

26. Yue, L.; Wang, L.; Han, J. Effects of rare earth on inclusions and corrosion resistance of 10PCuRE weathering steel. J. Rare Earths 2010, 28, 952-956.

27. Chen, X.; Li, Y. Fracture toughness improvement of austempered high silicon steel by titanium, vanadium and rare earth elements modification. Mater. Sci. Eng. A 2007, 444, 298-305.

28. Lan, J.; He, J.; Ding, W.; Wang, Q.; Zhu, Y. Effect of rare earth metals on the microstructure and impact toughness of a cast 0.4 C-5 Cr-1.2 Mo-1.0 V steel. ISIJ Int. 2000, 40, 1275-1282.

29. Qu, Y.; Xing, J.; Zhi, X.; Peng, J.; Fu, H. Effect of cerium on the as-cast microstructure of a hypereutectic high chromium cast iron. Mater. Lett. 2008, 62, 3024-3027.

30. Bramfitt, B. Planar lattice disregistry theory and its application on heterogistry nuclei of metal. Metall. Trans 1970, 1, 1987-1995.

31. Liu, X.; Yang, J.-C.; Yang, L.; Gao, X.-Z. Effect of Ce on inclusions and impact property of 2 Cr13 stainless steel. J. Iron. Steel. Res. Int. 2010, 17, 59-64.

32. Hamidzadeh, M.A.; Meratian, M.; Mohammadi Zahrani, M. A study on the microstructure and mechanical properties of AISI D2 tool steel modified by niobium. Mater. Sci. Eng. A 2012, 556, $758-766$.

(C) 2015 by the authors; licensee MDPI, Basel, Switzerland. This article is an open access article distributed under the terms and conditions of the Creative Commons Attribution license (http://creativecommons.org/licenses/by/4.0/). 